\title{
Lifestyle Experiences: Exploring Key Attributes of Lifestyle Hotels Using Instagram User-Created Contents in South Korea
}

\author{
Yoojin Han and Hyunsoo Lee *
}

check for updates

Citation: Han, Y.; Lee, H. Lifestyle Experiences: Exploring Key Attributes of Lifestyle Hotels Using Instagram User-Created Contents in South Korea. Sustainability 2021, 13, 2591. https://doi.org/10.3390/ su13052591

Academic Editors: Sérgio Moro, Ricardo Filipe Ramos and Mark A. Bonn

Received: 19 January 2021 Accepted: 24 February 2021 Published: 1 March 2021

Publisher's Note: MDPI stays neutral with regard to jurisdictional claims in published maps and institutional affiliations.

Copyright: (c) 2021 by the authors. Licensee MDPI, Basel, Switzerland. This article is an open access article distributed under the terms and conditions of the Creative Commons Attribution (CC BY) license (https:/ / creativecommons.org/licenses/by/ $4.0 /)$.
Department of Interior Architecture and Built Environment, Yonsei University, Seoul 03722, Korea; yoojin79@yonsei.ac.kr

* Correspondence: hyuns1@yonsei.ac.kr

Abstract: This study aims to investigate the key attributes of a steadily growing hotel sector (lifestyle hotels), which has shown great success in the global competitive market, by analyzing user-created content on Instagram. The dataset used in this study were prepared from a total of 20,999 lifestyle hotel posts and 24,262 boutique hotel posts created from 2013 to 2020 and retrieved using a Python web crawler. The locations, hashtags, and image data were analyzed based on frequency analysis using social network analysis methods and computer vision technology, after which they were visualized with a geographical information system and Gephi. The results demonstrated that lifestyle hotels share key attributes that differentiate them from others in terms of physical, geospatial, and experiential contexts. Design, location, and management type are the main attributes that comprise the distinct identity of each lifestyle hotel. Moreover, a lifestyle hotel is distinct from a boutique hotel in that staying in the former means consuming experiences with continuous changes. The information and knowledge gained from this research will contribute to bridging the gap between theoretical literature and the practical development of lifestyle hospitality.

Keywords: user-created content; big data; social network analysis; computer vision; lifestyle hotel; hospitality experience

\section{Introduction}

The level of competition in the hospitality industry has risen dramatically due to the increase in supply resulting from the emergence of new types of accommodations such as Airbnb [1]. Amidst tougher competition in the hospitality industry, revenue decline has been forecasted to continue in recent years [2]. To make matters worse, the global hospitality market has taken a huge hit due to the COVID-19 pandemic. According to HVS, a hospitality analytics provider, short-term profits fell by $63.7 \%$ in 2020 [3]. Even with the slight recovery forecasted, the RevPAR in the U.S. market is also expected to decline by $34.2 \%$ in 2021 compared to 2019 figures [4]. Under these circumstances, the role of hotels has transformed from the original function of providing accommodation for travelers [5]. In order to survive in the face of the rapidly changing market, hotel companies have developed a new type of niche hotel sector to attract customers, namely, lifestyle hotels. This sector has transformed the traditional hotel into a place where people consume experiences that match their individual lifestyles and have shown increased intention to visit because of the newly added values. In this new industry, global groups have established lifestyle brands as a means to deliver new value while also providing diverse programs, such as those related to business, culture, and leisure. Furthermore, unlike traditional hotels that provide wholly standardized services, lifestyle hotels focus on selected services valued by each consumer. In particular, in order to satisfy the unusual demand from millennials, global players have developed lifestyle hotels offering enriched experiences. Thus, these new hotels showcase exceptional design and provide more personalized services to suit each guest's lifestyle. Hotels can be a place for social gatherings, working, exercising, and/or simply relaxing for millennials [6]. The varied hospitality experiences clearly differentiate 
the lifestyle hotel sector from existing uniformed branded hotels [7]. The advent of the lifestyle hotel has caused a sensation in the hospitality industry and is poised to dominate the market in the coming years.

However, with the rapid growth of lifestyle hotels since mid-2010, the market has also become a red ocean. Even if they succeed in differentiating themselves from traditional hotels, they also lose their uniqueness with the expansion of the lifestyle market [8]. As the market size continues to grow, they have no option but to aim for standardization similar to branded hotels. Furthermore, the varieties of lifestyle hotel concepts are easily replicated and spread [9]. Many companies have also developed numerous "lifestyle" brands, each providing different sets of criteria, such as Indigo by the InterContinental Hotels Group, EVEN Hotels by IHG, Element by Westin, Aloft by Marriott, Andaz under Hyatt, and so on. The number of global lifestyle brands already exceeded 100 by June 2017 [10]. Specifically in South Korea, this higher growth is not that different even during the COVID-19 pandemic. In fact, although overall demand for rooms has decreased, hotel chains suffering from financial difficulties due to the pandemic have scrambled to open new lifestyle hotels in 2020 in order to cope with the increased demand for domestic travel and vacations [11-13]. Such a move is also seen as part of their advanced preparations to transition to a post-COVID-19 market [14]. Thus, these lifestyle hotels no longer just provide accommodations for travelers, but have also become destinations for people who love to travel but cannot yet travel abroad.

Meanwhile, in a market wherein all the new hotels are coming out with lifestyle brands, the expansion of lifestyle hotels has successfully broadened the boundary of the lifestyle sector. However, these hotels face the risk of losing their identity, as all the ones being launched also consider themselves a lifestyle brand [15]. Thus, it is no longer possible to provide personalized experiences tailored to individual lifestyles, which is the original selling point of lifestyle hotels. As lifestyle hotels failed to establish a specific sector and to differentiate themselves from other design-centric hotels, customers have no choice but to spend on "cookie-cutter" lifestyle experiences.

The hospitality environment of today is rapidly changing into a new sector with new rules. In such an uncertain marketplace, building a solid identity is essential for ensuring sustainable growth in the hospitality industry [16]. Moreover, as the concept of a lifestyle hotel is not limited to a sector, it is necessary to clarify that the meaning of "lifestyle" is expanding and evolving, although its value remains the same. In this context, a number of studies have explored the definition of a lifestyle hotel, including what it stands for and how it can be distinguished from other hotels. However, there still remains a gap between the definition from the literature and customers' perceived image of such hotels. Thus, identifying customers' opinions can help us understand what lifestyle value is.

In the age of lifestyle media, which has evolved and expanded consumers' choices, it is now possible to hear their opinions through user-generated content. Social media has drastically changed the traditional delivery of information in which producers created information and delivered it to users via one-way channels [17]. Furthermore, social media data enable companies to see product or service responses in faster and easier ways. The response by numerous "messengers" can either work in favor of a business or become a disadvantage; in comparison, user-created content is transparent and authentic. In particular, photos created and shared by users provide in-depth customer insights regarding the current state of the tourism industry [18]. At a time when much more innovative and exciting hospitality experiences are preferred by consumers, image-based, user-created content can help businesses catch up with the changing demands.

Therefore, the current study aims to identify the key attributes and experiences of this highly promising hotel sector and to reveal the emerging trends that drive the growth of the hospitality industry. These objectives are realized through an investigation of how the guests share their lifestyle hotel experience by looking into social big data. This research analyzes and evaluates user-created lifestyle hotel content compared to boutique hotel content on Instagram with the case of South Korea. 
In exploring this topic, the study proposes the following research questions:

1. What are the most common attributes of lifestyle experience that are illustrated in user-created lifestyle hotel content on Instagram?

2. How do guests perceive the experience in a lifestyle hotel compared to that in a boutique hotel?

3. What is the difference between the shared image of a lifestyle hotel and its theoretical definition?

4. What are the dynamics of the lifestyle hotel market in geospatial and experiential contexts?

5. Do the emerging trends help shape the image of the continuously growing lifestyle hotel sector?

The literature review establishes an understanding of the current definition of the lifestyle hotel sector. Then, the shared attributes of lifestyle hotels are explored. Usercreated content on Instagram, an image-sharing social networking site (SNS), are analyzed. Instagram is a representative photo-sharing platform that is widely used throughout the world. Analyzing user-created content on Instagram provides us with various information based on images that show specific spaces or targets [19]. Images are a communication tool for understanding impressions of physical environments; thus, visual methods allow us to understand effectively how users view the physical world [20]. The hashtags provide complex materials, such as information, thoughts, and emotions towards spaces or targets illustrated in the photos. In particular, an Instagram post with a location tag can help us understand social behaviors within a particular place from diverse perspectives [21,22]. Therefore, Instagram data show users' holistic experiences in a place and their perceptions of these specific locations.

On this premise, this study explores the attributes that are illustrated in customers' experiences of lifestyle hotels. This study adopts a big data approach for analyzing imagebased user-created content on Instagram. Then, by comparing lifestyle and boutique hotels, we investigate the key attributes in terms of geospatial and experiential contexts. The study aims to present an understanding of lifestyle hotels' continuous growth and suggest how future lifestyle experiences in the hospitality domain can be designed. The results of the study can also provide guidelines for sustainable growth in terms of marketing and spatial programming. Finally, this research suggests the use of social media big data in investigating future hotel experiences from users' perspectives.

\section{Literature Review}

\subsection{Lifestyle Hotel}

Global hotel groups have used the word "lifestyle hotel brand" as a means of describing a new type of hotel that represents individual lifestyles and captures customers' preferences in response to individual travelers' growing demand for a wide range of experiences that appeal to their individual lifestyles [23]. Lifestyle hotel brands have mainly targeted the so-called "millennial generation," also known as "Generation Y" [24]. Millennials are a generation interested in having new experiences; they also value vacation time and prefer hyper-personalized services in accordance with their higher spending power in the field of tourism. Compared to older generations, millennials visit hotels for more diverse activities, such as having fun, unplugging or escaping from their daily lives, celebrating a special occasion, gaining inspiration, and/or attending events [6]. According to the hospitality and leisure report conducted by the $\mathrm{PwC}$, "people eat, sleep, play games, cement friendships, and seek cures in H\&L facilities" [25], as lifestyle hotels offer diverse facilities, customized services, as well as unique interiors and architectures, which cannot easily be found in traditional branded hotels [16]. Given that an increasing number of travelers are now seeking experiential aspects and no longer only consider a comfortable atmosphere or the quality of service, standardized hotels have become insufficient for nextgeneration consumers [26]. Therefore, since the mid-20th century, a number of lifestyle hotel brands have been launched by differentiating themselves from traditional hotels. 
The term "lifestyle hotel" was first used in 1988 by the W hotel brand, a global upscale hotel chain operated by Marriott International [15]. The hotel chain scale of lifestyle brands depends on each brand; some of them are upscale or luxury, whereas the others are considered budget brands. Thus, the traditional chain scale, which was previously based on the average daily rate, is no longer suitable for identifying this new type of hotel.

Past efforts to clarify the concept of lifestyle hotels have focused on their differences from traditional standardized brand chains [27]. Previous studies have tried to clarify the concept of lifestyle hotels by defining their common characteristics as follows: (1) eye-catching architecture and interior design, (2) use of smart technology, (3) modern atmosphere, (4) personalized services, and (5) enriched experiences [7,9,28]. Furthermore, Kosar (2014) highlighted the "live-work-play environment" of lifestyle hotels offering artistic, design-centric, and fashionable experiences [29]. Additionally, lifestyle hotels provide diverse experiences for "wellness and life enrichment" [16]. Likewise, previous studies have emphasized the experiential aspects and physical characteristics in developing their academic definition of "lifestyle hotels" [16,29-32]. Among these characteristics, the most conceptually significant were a sense of belonging through highly customized service and appealing to every individual lifestyle [8].

However, the concept of lifestyle hotels has not been defined clearly, because they are often confused with boutique hotels. Some research and hospitality organizations still group boutique and lifestyle hotels together. This is due to the fact that the former borrows features from the latter [33]. Nevertheless, according to the Boutique Lifestyle Leaders Association (BLLA), there is a growing consensus that definite differences exist between them [28]. Hence, we set up and empirically address the following questions: How do guests perceive the experience in a lifestyle hotel compared to that in a boutique hotel? What is the difference between the shared image of a lifestyle hotel and its theoretical definition?

As lifestyle hotels that have expanded and adopted global franchising in recent years $[16,27,32]$, they now find it difficult to meet all their customers' needs and preferences compared to smaller, independent hotels [8]. Moreover, lifestyle hotels operated by larger hotel companies, with high levels of uniformity and consistency, have also become standardized [10]. Therefore, the literal meaning of lifestyle hotels remains vague. In this circumstance, lifestyle hotels reflect current and future trends and can cater to the demands of the new-normal lifestyle hotels [15]. STR, who are analytics specialists in the hospitality domain, defined lifestyle brands as a "group of hotels operating under the same brand that is adapted to reflect current trends" [34]. Hence, the definition of such a term is not only limited to adopting the principles of boutique hotels but also reflects the newly emerging preferences of new lifestyle consumers [33]. Based on this, this study investigates the dynamics of the lifestyle hotel market in physical, geospatial, and experiential contexts in terms of lifestyle trends.

\subsection{User-Created Contents on Instagram}

According to the BLLA, over 75\% of travelers share travel photos on social media [35]. User-created content in the hospitality sector shows guests' real-time experiences and activities. If traditional psychographic research gives us deep insights into consumers thoughts and desires, social media-driven data provide us with information regarding the ever-changing customer landscape [33].

Many studies have explored user-created content in the hospitality domain. Instagram is a popular photo-sharing SNS, along with Facebook and Twitter [36]. Instagram provides users with a variety of information- and image-based experiences [19]. An Instagram post includes creator-related features (ID and profile), contextual features (date/time and location), and content features (image, hashtags, caption, and comments). Initial studies on SNS have mainly focused on analyzing the motivations, characteristics, and emotions behind the consumption of a particular product, service, or space in various domains. Instagram data also show traces of users' experiences and activities in a specific 
location, as users are allowed to tag the location information for particular places [37]. The collected data thus reflect individual actions, perceptions, and interactions, which ultimately represent urban social behaviors [21,38]. Instagram data help in understanding user behaviors from social, cultural, and environmental perspectives [22]. Furthermore, user-created content on Instagram not only indicates their perceptions of a place but also affects other users' future behaviors [39].

Photos that users post on image-based social media represent their interests at a given moment, which reflect their activities, perceptions, and interactions $[40,41]$. Therefore, images on Instagram posts are a crucial social currency [19]—one of the most important kinds of data with which to understand the modern tourism industry [18]. Given that images are said to contain more than thousands of words, it is difficult to analyze many images due to the lack of sophisticated image-processing technologies. Nevertheless, deep learning-based computer vision technology can be used to identify image content automatically. With the help of this technology, Hu analyzed numerous Instagram images for the first time and classified them into eight categories: Friends, Food, Gadget, Captioned Photo, Pet, Activity, Selfie, and Fashion [22]. Jaakonmäki analyzed the visual features of Instagram images by utilizing machine learning-based Clarifai API [42]. In order to gain insights from photos, other studies have also been conducted to analyze images on social media using computer vision technology, which would have been otherwise difficult to do one by one.

Therefore, this study proposes a content analysis on the text as well as image content generated by users to retrieve key attributes of a new type of hotel. This study explores the most common attributes of lifestyle experience that are illustrated in user-created lifestyle hotel content on Instagram.

\section{Materials and Methods}

The aim of this study was to investigate guests' experiences in lifestyle hotels and to derive these hotels' key attributes by analyzing user-created content on Instagram. The study adopted mixed methods based on a quantitative approach in order to extract in-depth understanding from various types of Instagram data.

The methods and scope of this study are presented in Figure 1.

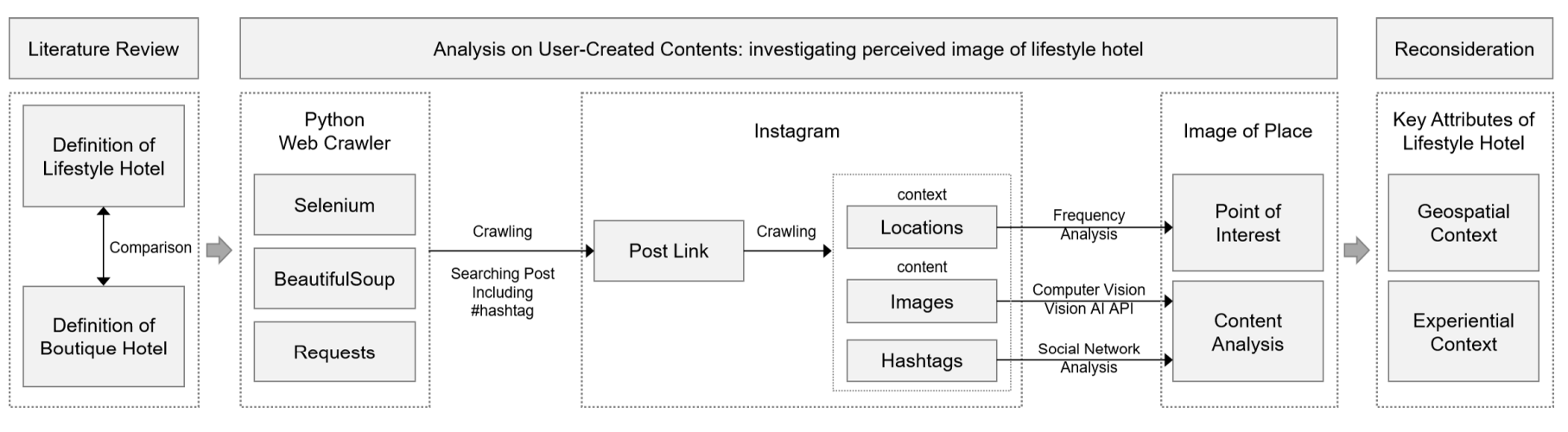

Figure 1. Research framework.

First, based on the literature reviews, the definition of a lifestyle hotel compared to a boutique hotel was investigated.

Second, Instagram posts containing lifestyle hotel and boutique hotel hashtags (\#) were retrieved. We developed a Python web crawler for data collection using several open-source libraries. The collected data from Instagram posts included dates, locations, images, hashtags, captions, number of likes, and so on.

Third, the content and contextual features of the collected data were analyzed. Point of interest (POI) was defined based on the frequent locations in Seoul City that had gained public attention. In addition, we identified the patterns of space consumption in terms of 
lifestyle hospitality. The content features, which included hashtags and images, were analyzed. Then, we conducted a social network analysis (SNA) on the hashtags to investigate the key attributes of the target hotels. Additionally, this study adopted a deep-learning approach for analyzing Instagram image content. The images were evaluated using computer vision technology to explore the main attributes that gained public interest as shared in their posts.

Finally, after comparing the definition from the literature and the perceived image of lifestyle hotels with those of boutique hotels, we reestablished the concept of lifestyle hotels and extracted its key attributes. Such information in terms of geospatial and experiential contexts can be used by brands to devise ways to help them grow in the global market.

\subsection{Data Collection}

This study explored customers' perceptions of lifestyle hotels by analyzing big data retrieved from their Instagram posts. Figure 2 shows the basic structure of an Instagram post. The data collected from a post included ID, location, image (or video), caption, hashtags, comments, number of likes, and the date of posting. From Instagram, posts can be searched using a specific hashtag, location, or user ID, and the results are shown in the chronological order. For this research, we collected Instagram posts containing lifestyle hotel and boutique hotel hashtags, as the hashtags generated by a user who posted a related image represent the same explanation for other users [43].

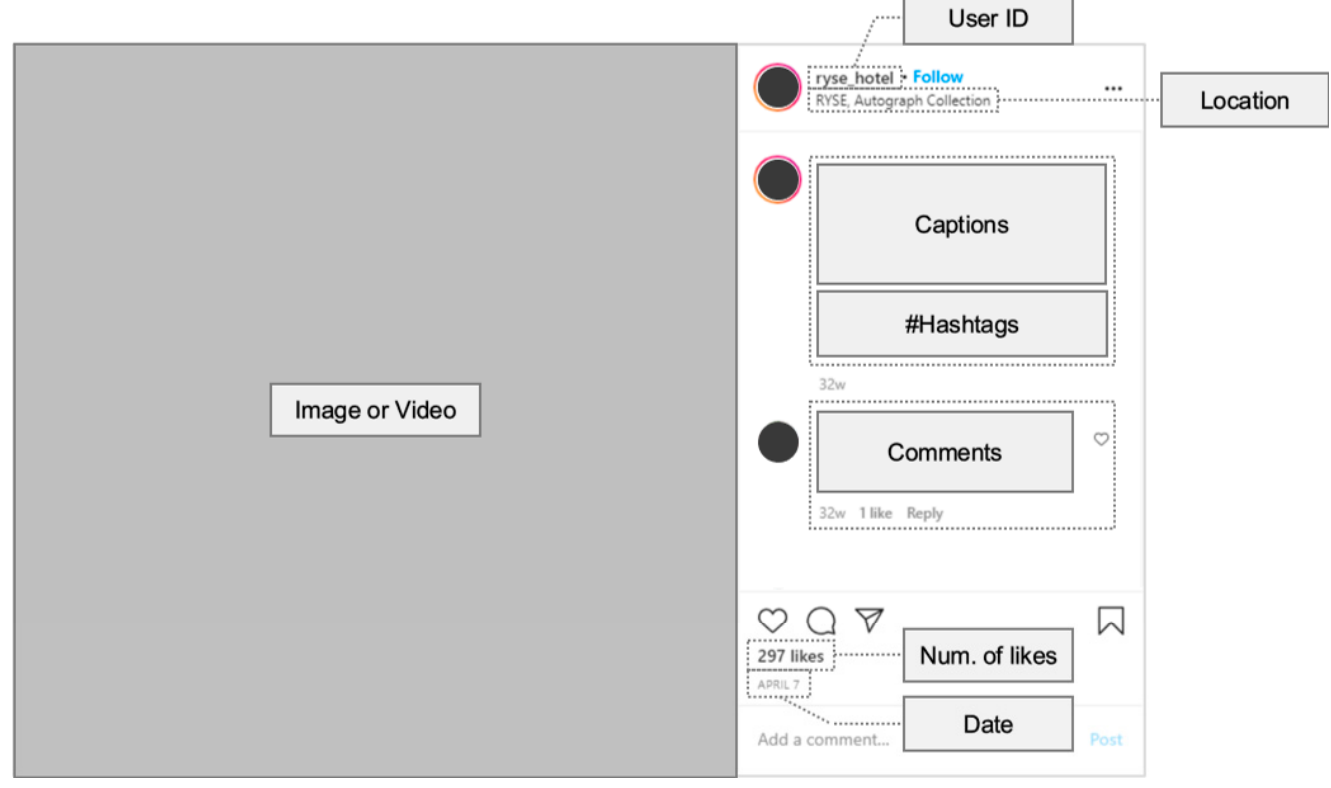

Figure 2. Content and context features of an Instagram post.

For dataset preparation, we developed an automatic crawler with Python using several libraries, namely, Selenium, BeautifulSoup, and Requests. The web crawler first collected the links of the searched posts and then extracted different kinds of data from each link. The collected data were pre-processed by eliminating redundant post links. Thus, searchable posts in the data collection period, which contained lifestyle and boutique hotel hashtags (\#lifestylehotel and \#boutiquehotel, respectively), were gathered. The geographical scope of this research was mainly focused on the city of Seoul, South Korea, where many hotels are currently in development. Therefore, hashtags in both the Korean and English languages were used during data collection. The collected data from Instagram posts included contextual features (location and date of creation), content features (image, hashtag, and caption), and engagement (number of likes). Multiple images can be uploaded in a single post, but only the representative image that the followers would see first were included in 
the dataset. The data collection took place in two periods from the months of September 2020 to November 2020.

\subsection{Data Analysis}

Five types of data were gathered: location, date of creation, image, hashtag, and number of likes. The data were categorized into three types: contextual feature (location and data), content feature (image and hashtag), and engagement level (number of likes). Among them, we focused on image, hashtag, and location, which showed the perceived images of a specific place. Each piece of data had a different type; therefore, we analyzed the collected data using different methods.

\subsubsection{Contextual Feature Analysis}

First, we selected highly ranked locations as POIs through a frequency analysis, which examined 20,886 lifestyle hotel posts and 24,161 boutique hotel posts. The geographical standard of the city was based on the urban planning system of Seoul [44]. POI was defined on the basis of the spatial analysis conducted to find the locations that people often visited and perceived as a lifestyle or a boutique hotel.

\subsubsection{Content Feature Analysis}

The content features (hashtags and images) were analyzed to identify the shared characteristics and hospitality experiences. We conducted SNA on the collected hashtags to gain an understanding of users' perceptions of each hotel. Additionally, we utilized computer vision technology to analyze the numerous images collected.

For hashtag analysis, the top 100 hashtags with higher frequencies for each hotel were selected to identify the shared characteristics. In this stage, hashtags that only indicated "hotel" were excluded from the analysis. Then, a semantic analysis was conducted on how Instagram users perceived lifestyle and boutique hotels through an SNA on the key hashtags. This study utilized the metrics for SNA provided by Gephi, a visualization and exploration software for the network. SNA was performed by calculating the eigenvector centrality, which implied the significance of a node within a network [45]. Following this process, the research investigated the meaningful hashtags found in SNS posts. Based on the results obtained, a semantic analysis was conducted on how Instagram users perceived lifestyle hotels and their main differences from boutique hotels.

In addition, this study used computer vision technology to examine the main features that caught people's attention, as illustrated in the images they posted. Using deep learningbased image recognition technology allowed us to understand what the images represented in the context of big data analytics. That this technology can recognize objects expressed in images and classify them automatically, then the unstructured image data can be converted into structured data (i.e., words). Therefore, it is advantageous to automatically process large quantities of various images.

Furthermore, an optimized computer vision API provided by Google, Vision AI, was adopted for image analysis. Based on pre-trained machine learning models, Vision AI can recognize objects and texts that appear in an image and automatically identify the content of such an image [46]. Specifically, in this study, image recognition and analysis proceeded as follows. First, several labels (class) were assigned for each image, showing the results with a predicted value (score). The labels represented the characteristics of an image by categorizing it into millions of predefined categories. The score represented a probabilistic value indicating that what the image stood for was the assigned label. On average, nine labels were assigned to each image in this study. Then, a set of descriptive labels was designed for the image dataset. As this study sought to find major features from a huge image dataset, instead of solely calculating the frequency, the key labels were examined based on the frequency count multiplied by the predicted scores. Then, the major labels were classified based on five categories defined by visual methods in hospitality research [20] and dimensions of atmospherics [47-51]. 
Finally, based on the obtained results, we analyzed the key attributes of lifestyle hotels in comparison with boutique hotels and reconsidered the former's identity and definition in the future hospitality sector.

\section{Results}

\subsection{Basic Dataset Statistics}

Table 1 shows the basic statistics of the Instagram dataset. In this study, 20,999 and 24,262 links for lifestyle and boutique hotel posts, respectively, were retrieved. The collected posts were created between February 2013 and November 2020. As the lifestyle hotel expanded intensely from the early 2010s, all collected posts were included in the dataset. All the data available, including locations, hashtags, and images, were gathered from the post links. Lifestyle hotel posts showed 2209 kinds of locations, whereas boutique hotel posts had much more diverse location information $(n=6534)$. Even though a series of photos can be shared in one post, only the first image per post was collected. As a result, 20,866 lifestyle hotel images and 24,161 boutique hotel images were gathered. Next, 43,586 hashtags were retrieved from lifestyle hotel posts, and 63,505 hashtags were extracted from boutique hotel posts. On average, one post included a similar number of hashtags (18 in a lifestyle hotel post and 17 in a boutique hotel post). Additionally, posts for both kinds of hotels received similar numbers of likes, on average: 132 likes for lifestyle hotels and 147 likes for boutique hotels. This means that both lifestyle and boutique hotel posts showed similar levels of engagement.

Table 1. Statistical summary of the Instagram dataset.

\begin{tabular}{ccc}
\hline Data & Lifestyle Hotel & Boutique Hotel \\
\hline Post links (total) & 20,999 & 24,262 \\
Images (total) & 20,866 & 24,161 \\
Hashtags (total) & 43,586 & 63,505 \\
Hashtags (per post) & 18 & 17 \\
Locations (total) & 2209 & 6534 \\
Likes (mean) & 132 & 147 \\
Date of Creation & June 2013 to November 2020 & February 2013 to November 2020 \\
\hline
\end{tabular}

\subsection{Contextual Features}

\section{Location}

This study explored POI by analyzing the location data of Instagram posts. In the case of lifestyle hotels, about $65 \%$ of the posts tagged the locations ( $n=13,587)$. In comparison, only $27 \%$ of boutique hotel posts had location data $(n=6534)$. Table 2 highlights the most popular locations found in lifestyle and boutique hotel posts within Seoul during the data collection period.

Most people visited branded hotels as lifestyle hotels in the city center. Lifestyle hotel locations were the most common in downtown Seoul. The most frequently visited lifestyle hotel was Hotel Cappuccino, due to the fact that they used the concept of "lifestyle hotel" in their marketing. In contrast, boutique hotel posts were created in several independent hotels (i.e., the hotels that were not part of a global chain and were operating independently). Boutique Hotel Le Lit and L'Escape Hotel had the highest frequencies, although they only accounted for $1.77 \%$ of locations. Likewise, there were only a few branded hotels that people commonly perceived as boutique hotels compared to lifestyle hotel locations. These results indicate that the concept of a lifestyle hotel is highly relevant to a particular branded place. 
Table 2. Frequent locations of hotels.

\begin{tabular}{ccccccc}
\hline Type $^{\mathbf{1}}$ & Rank & Location Name & Freq. & $\mathbf{\%}^{\mathbf{2}}$ & Regions & Type \\
\hline & 1 & Hotel Cappuccino & 1816 & 82.21 & Sub center & Branded \\
L & 2 & L7 HOTEL-City Center & 83 & 3.76 & City center & Branded \\
& 3 & RYSE & 62 & 2.81 & Sub center & Branded \\
& 4 & L7 HOTEL-Gangnam & 61 & 2.76 & Sub center & Branded \\
& 5 & PATIO7 HOTEL & 37 & 1.67 & Sub center & Branded \\
\hline B & 1 & Boutique Hotel, Le Lit & 80 & 1.22 & City center & Independent \\
& 2 & L'Escape Hotel & 36 & 0.55 & City center & Independent \\
& 3 & Hotel Crescendo Seoul & 4 & 0.06 & Sub center & Independent \\
& 4 & THE PLAZA & 4 & 0.06 & City center & Branded \\
& 5 & Mondrian Seoul Itaewon & 2 & 0.03 & Sub center & Branded \\
\hline
\end{tabular}

${ }^{1} \mathrm{~L}=$ lifestyle hotel, $\mathrm{B}=$ boutique hotel. ${ }^{2}$ Percentage = frequency of location divided by total number of locations.

Figure 3 shows the spatial distributions of lifestyle and boutique hotel locations in Seoul by the number of posts. As can be seen, most lifestyle and boutique hotels can be found in the city center and sub-city center. Whereas lifestyle hotel locations covered a relatively broad area, the locations of the boutique hotel were concentrated in the center of the city.

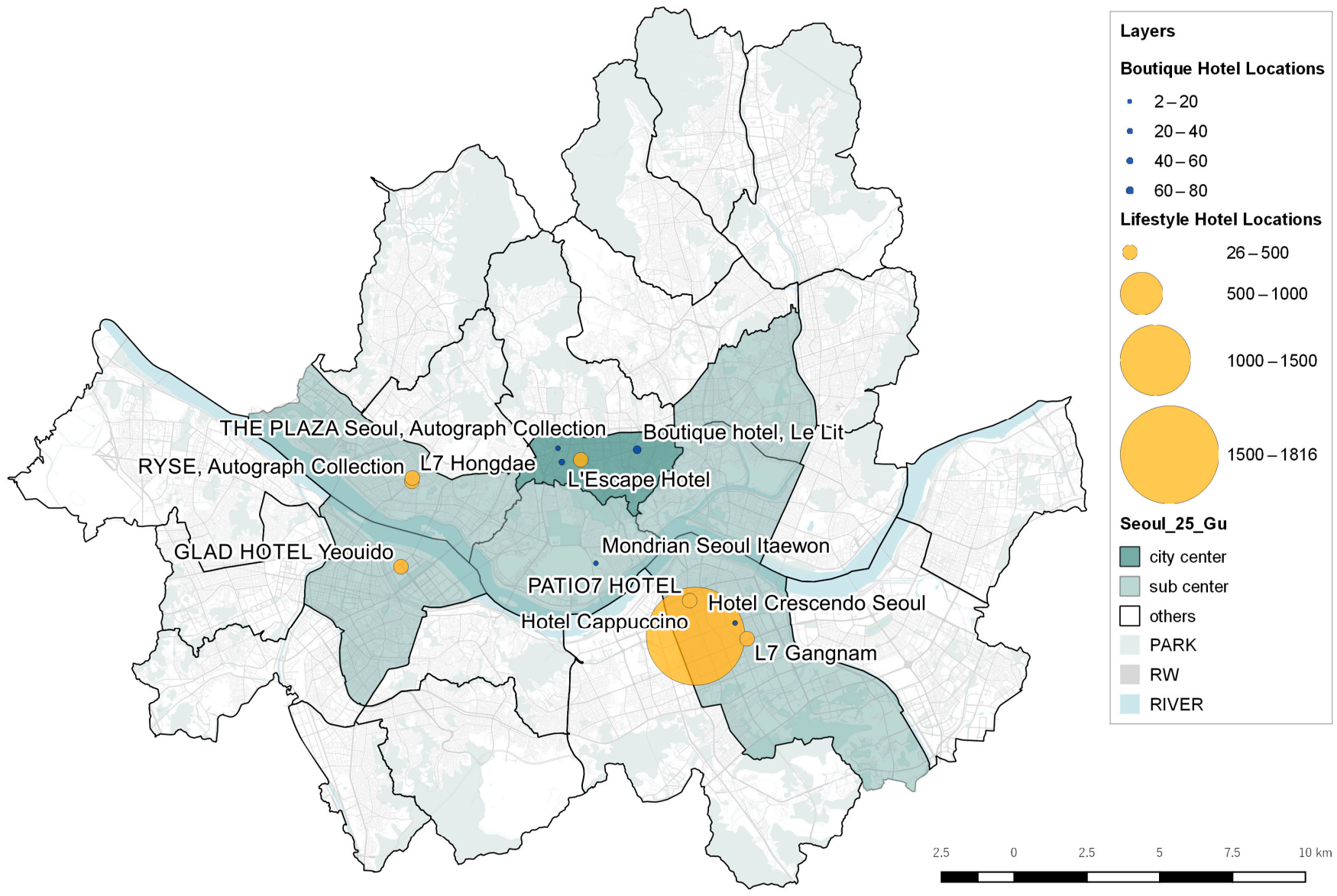

Figure 3. Distributions of lifestyle and boutique hotels in Seoul.

\subsection{Content Features}

This study investigated key attributes by analyzing content features (hashtags and images) using SNA and image analysis via computer vision technology. In this study, 43,586 hashtags related to lifestyle hotels and 63,505 hashtags related to boutique hotels 
were retrieved from the dataset. The average number of hashtags per post was similar, with about 18 hashtags for a lifestyle hotel and 17 hashtags for a boutique hotel. For the image analysis, a total of 20,866 lifestyle hotel images and 24,161 boutique hotel images were used. On average, nine labels were assigned to identify the content of the image.

\subsubsection{Hashtag Analysis}

As a result of analyzing hashtag frequency, the top 100 related hashtags were selected. Common hashtags were related to hotel concepts, architecture and interior design, vacation and travel, facilities, hospitality and lifestyle trends, and hotel brands and regions.

Figures 4 and 5 illustrate the results of the network analysis of the top 100 lifestyle hotel and boutique hotel hashtags based on eigenvector centrality. As can be seen, the network of hashtags was densely connected in both cases (i.e., average clustering coefficients were 0.81 and 0.948 for lifestyle and boutique hotels, respectively, indicating a densely connected network) [52].

An analysis of lifestyle hashtags indicated that "boutique hotel" and "design hotel" had higher centralities in terms of hotel concept (the eigenvector centralities were 0.981 and 0.900 , respectively). Following this, the most outstanding hashtags were related to hospitality interior and architecture, such as "design" (0.970), "interior design" (0.966), "hotel design" (0.919), "interior" (0.896), "hotel style" (0.881), and "architecture" (0.874). Additionally, traditional travel and vacation keywords also seemed to be important, including "travel" (1), "holiday" (0.972), "vacation" (0.921), "instatravel" (0.882), and "travelgram" (0.857). From the spatial program context, "hotel room" (0.981), "rooftop" (0.811), and "restaurant" (0.756) hashtags were identified. Unlike conventional travel keywords, lifestyle hotel posts had hashtags describing urban experiences, such as "urban retreat" (0.568), "urban oasis" (0.535), and "urban lifestyle" (0.410). Some hashtags, such as "hotel life" (0.954) and "staycation" (0.812), reflected new hospitality trends such as spending one's vacation in a hotel, whereas others, such as "lifestyle" (0.911) and "hotel lifestyle" (0.743), highlighted the concept of lifestyle in the hotel context. Some hashtags even showed relatively weak centrality, such that the city of "Seoul" (0.589) and a specific hotel brand, "Hotel Cappuccino" (0.536), emerged.

The hashtag analysis in boutique hotel posts indicated that such hotels strongly shared similar concepts with other hotels or accommodations: "luxury hotel" (1), "design hotel" (1), "resort" (0.991), and "Airbnb" (0.932). Moreover, in terms of hotel size, two keywords emerged, namely, "small luxury hotels" (0.970) and "small hotels" (0.875). Above all, hashtags related to travel and vacation were very significant: "travel" (1), "travelgram" (1), "vacation" (1), "instatravel" (1), "holiday" (1), "wanderlust" (1), "tourism" (0.996), "explore" (0.950), and "adventure" (0.940). Keywords related to architecture and interior design also had great importance in boutique hotel posts, including "interior design" (1), "hotel design" (1), "architecture" (0.996), and "design" (0.988). In terms of hotel facilities, "hotel room" (1) was the most important hashtag, followed by "restaurant" (0.979), "spa" (0.968), and "pool" (0.941). Additionally, the more outstanding keywords related to hospitality and lifestyle trends were linked to luxury, including "luxury lifestyle" (1), "luxury" (0.996), "luxury travel" (0.996), and "luxury living" (0.910). Some hashtags indicated newly emerging hospitality trends, such as "hotel life" (1) and "staycation" (1), but traditional hospitality experiences were also found, such as "relax" (0.988). Hashtags reflecting nature, such as "nature" (0.991) and "beach" (0.968), were also found in boutique hotel posts. Interestingly, the hashtag "stay safe" (0.883), one of the up-to-date keywords used in the COVID-19 era, was highly ranked in the analysis of boutique hotel posts. 


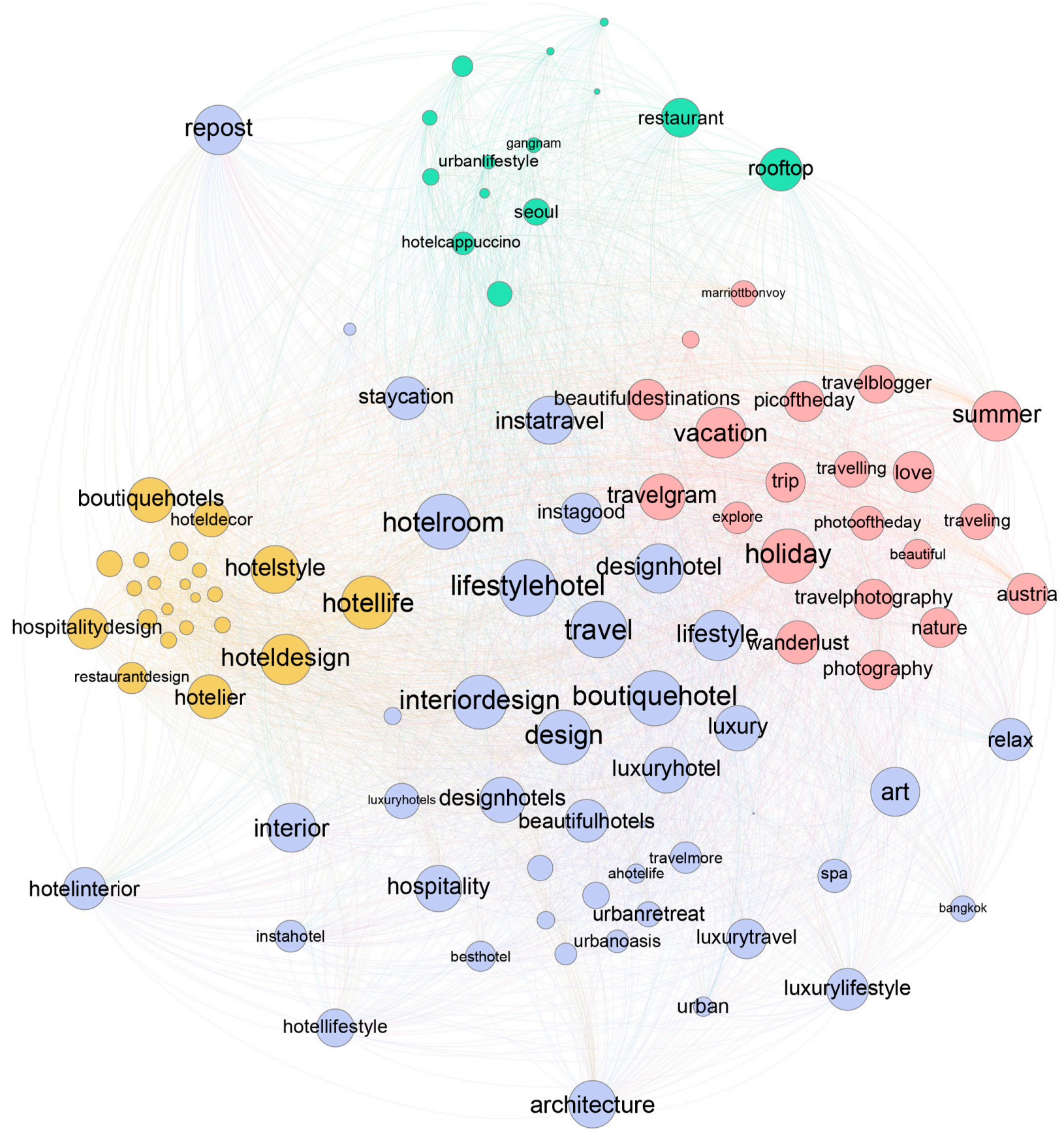

Figure 4. Visualization of lifestyle hotel hashtag analysis.

Likewise, the hashtag analysis revealed that guests showed similar attributes for lifestyle and boutique hotels. First of all, the hashtags "interior design" and "hotel room" were most frequently used in both lifestyle and boutique hotel posts. In addition, vacation and travel keywords that could appear in general hotel-related content were also noted in both lifestyle and boutique hotel experiences. However, there were still some differences between these two sectors. Whereas boutique hotel-related posts greatly used general travel-related keywords, lifestyle hotel posts had hashtags describing urban experiences, such as "urban lifestyle" and "rooftop bar." That these hashtags related to travel appeared together in urban hotel posts shows an emerging trend in travel and tourism: People want to spend their vacation in an urban hotel (i.e., "hocance" or hotel + vacance). On the contrary, in the case of boutique hotels, hashtags for urban experiences were significantly missing. Instead, nature and outdoor leisure had become highly relevant to the boutique 
hotel experience. Guests also showed a strong connection between the boutique hotel experience and luxury. Finally, hashtags indicating the size of the facility were only featured in boutique hotel posts and not in lifestyle hotel posts.

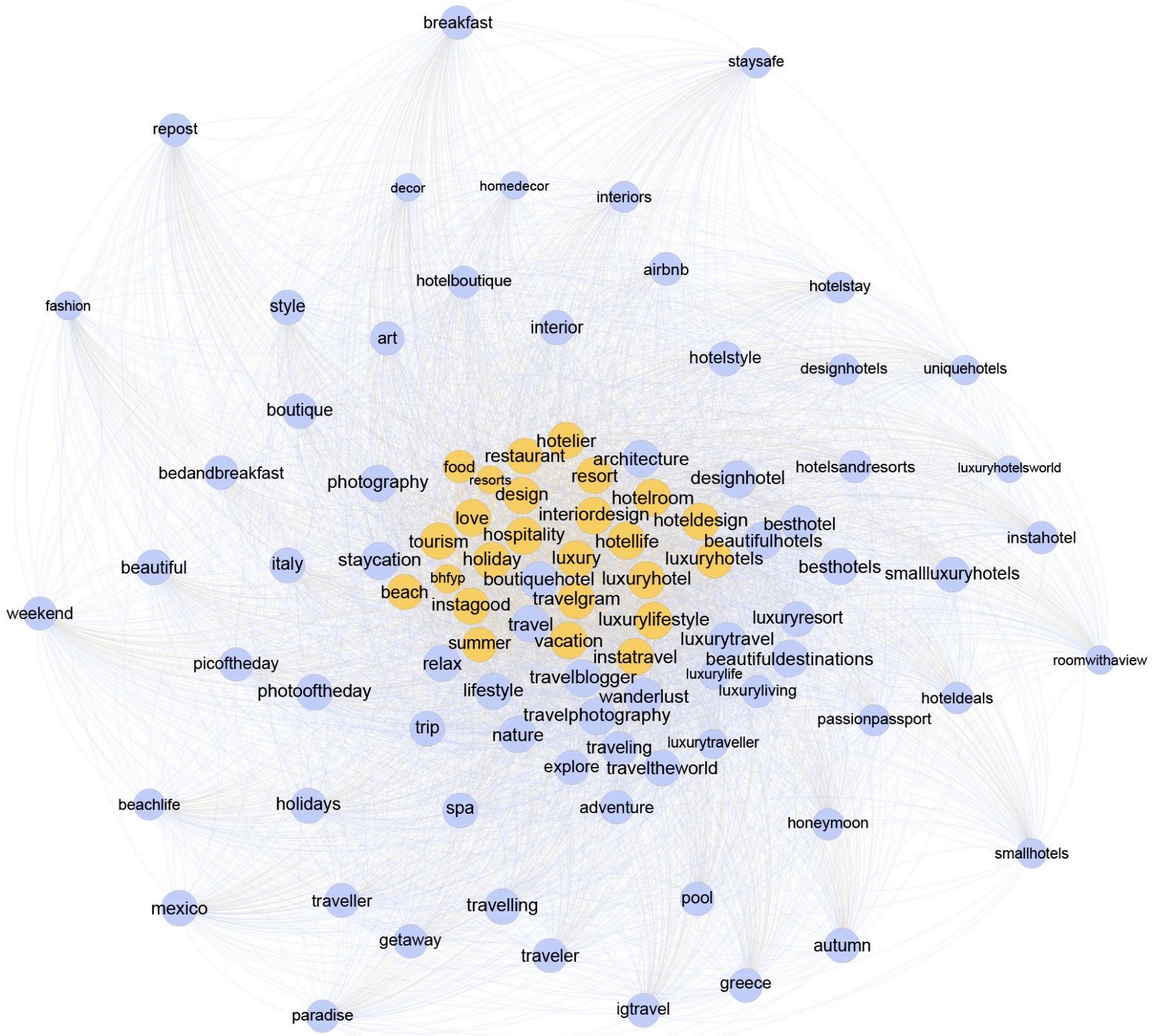

Figure 5. Visualization of boutique hotel hashtag analysis.

\subsubsection{Image Analysis}

Table 3 shows the results of the most common labels from the dataset of collected images. In terms of lifestyle hotels, the main visual features that caught people's attention had to do with interior design and architecture. Many labels belonged to the "design" category. The most common labels were "room" (29.52\%), "interior design" $(23.77 \%)$, and "furniture." These results reflect the most basic function of a hotel: staying. Next, "general interior" elements, such as "wall" (8.89\%), "floor" (6.76\%), and "ceiling" (6.48) appeared. In addition, FF\&E features were shown frequently, including "furniture" $(22.2 \%)$, "table" (9.98\%), "bed" (6.16\%), and "lighting" (5.22\%). Architecture-related terms, including "building" (18.92\%), "architecture" (16.82\%), and "property" (16.25\%), were important 
parts of the images. Furthermore, users visually focused on "activities," "nature," and "food" content.

In boutique hotels, architecture and interior design features were also the most crucial. As with lifestyle hotels, the most outstanding elements that caught people's attention in boutique hotel images were under the "design" category, including facilities, general interior, FF\&E, and architecture. In addition, boutique hotel posts also showed "activities," "nature," and "food" content. However, the findings indicated some differences between lifestyle and boutique hotels. First, in terms of facilities, about $4 \%$ of boutique hotel images showed "swimming pool," whereas it was not a very major element in lifestyle hotel images. Additionally, the label of "design" appeared only in the lifestyle hotel case, thus strengthening the general interior attributes in the shared hotel images.

Additionally, whereas the images of lifestyle hotels tended to show the urban landscape, such as "city" (4.28\%) and "urban area" (3.55\%), the images of boutique hotels showed more vacation and nature attributes in "natural landscape" (3.77\%) consisting of "sea" $(4.49 \%)$, and "nature" (3.23\%). Users also posted a number of food-related images. "Food" attributes were highly ranked in lifestyle hotel images and appeared more frequently than in boutique hotel images. Specifically, "drink" (4.15\%), "meal" (3.75\%), and "brunch" (3.13\%) were frequently illustrated only in lifestyle hotel images.

In both cases, architecture and interior design features comprised a considerable part of the posted images. Regarding lifestyle and boutique hotels, users posted an overwhelming number of spatial images showing room photos, furniture, and buildings. In particular, design-related visual attributes seemed to be slightly more important in lifestyle hotel posts. Except for the guestroom, dining experiences were expressed in many images in both cases, although slightly more frequently in lifestyle hotel images. In addition, natural and holiday settings were also a key attribute of the images. However, lifestyle hotels differed from boutique hotels in that more urban experiences were depicted in the images. The biggest difference was that many lifestyle hotel guests recorded their experiences in the city and urban areas, whereas boutique hotel guests only shared natural landscapes.

Table 3. Top 40 labels of Instagram images.

\begin{tabular}{|c|c|c|c|c|c|c|c|}
\hline \multirow{2}{*}{ Category } & \multirow{2}{*}{ Attributes } & \multicolumn{3}{|c|}{ Lifestyle Hotel } & \multicolumn{3}{|c|}{ Boutique Hotel } \\
\hline & & Labels & Rank & $\%^{1}$ & Labels & Rank & $\% 1$ \\
\hline \multirow[t]{21}{*}{ Design } & Facilities & Room & 1 & 29.52 & Room & 1 & 29.68 \\
\hline & & Living room & 26 & 5.02 & Bedroom & 15 & 7.37 \\
\hline & & Bedroom & 19 & 6.13 & Living room & 28 & 4.62 \\
\hline & & & & & Swimming pool & 34 & 4.07 \\
\hline & General & Interior design & 2 & 23.77 & Interior design & 2 & 23.70 \\
\hline & Interior & House & 8 & 10.55 & House & 7 & 16.19 \\
\hline & & Wall & 10 & 8.89 & Wall & 10 & 9.68 \\
\hline & & Floor & 14 & 6.76 & Home & 12 & 9.15 \\
\hline & & Ceiling & 17 & 6.48 & Floor & 16 & 7.23 \\
\hline & & Home & 20 & 5.40 & Ceiling & 20 & 6.60 \\
\hline & & Design & 28 & 4.62 & & & \\
\hline & FF\&E & Furniture & 3 & 22.22 & Furniture & 4 & 22.83 \\
\hline & & Table & 9 & 9.98 & Table & 11 & 9.17 \\
\hline & & Bed & 18 & 6.16 & Bed & 17 & 7.11 \\
\hline & & Lighting & 22 & 5.22 & Lighting & 26 & 5.25 \\
\hline & & Bed sheet & 38 & 3.54 & Bed sheet & 30 & 4.24 \\
\hline & & & & & Bed frame & 32 & 4.08 \\
\hline & Architecture & Building & 4 & 18.92 & Property & 3 & 23.44 \\
\hline & & Architecture & 5 & 16.82 & Building & 5 & 20.53 \\
\hline & & Property & 6 & 16.25 & Architecture & 6 & 17.02 \\
\hline & & Real estate & 24 & 5.18 & Real estate & 13 & 8.17 \\
\hline
\end{tabular}


Table 3. Cont.

\begin{tabular}{|c|c|c|c|c|c|c|c|}
\hline \multirow{2}{*}{ Category } & \multirow{2}{*}{ Attributes } & \multicolumn{3}{|c|}{ Lifestyle Hotel } & \multicolumn{3}{|c|}{ Boutique Hotel } \\
\hline & & Labels & Rank & $\%^{1}$ & Labels & Rank & $\% 1$ \\
\hline \multirow[t]{11}{*}{ Setting } & Activities & Vacation & 30 & 4.49 & Vacation & 18 & 7.00 \\
\hline & & Leisure & 35 & 3.90 & Leisure & 27 & 4.63 \\
\hline & Landscape & City & 32 & 4.28 & Natural landscape & 37 & 3.77 \\
\hline & & Urban area & 37 & 3.55 & & & \\
\hline & Nature & Sky & 7 & 11.99 & Sky & 8 & 15.88 \\
\hline & & Tree & 12 & 7.28 & Tree & 9 & 13.02 \\
\hline & & Plant & 21 & 5.28 & Plant & 14 & 7.47 \\
\hline & & Water & 31 & 4.28 & Water & 22 & 6.00 \\
\hline & & & & & Sea & 29 & 4.49 \\
\hline & & & & & Cloud & 38 & 3.58 \\
\hline & & & & & Nature & 40 & 3.23 \\
\hline \multirow[t]{7}{*}{ Service } & Food & Food & 11 & 8.49 & Food & 19 & 6.91 \\
\hline & & Cuisine & 15 & 6.71 & Cuisine & 23 & 5.60 \\
\hline & & Dish & 16 & 6.60 & Dish & 24 & 5.46 \\
\hline & & Ingredient & 27 & 4.97 & Ingredient & 31 & 4.22 \\
\hline & & Drink & 33 & 4.15 & & & \\
\hline & & Meal & 36 & 3.75 & & & \\
\hline & & Brunch & 40 & 3.13 & & & \\
\hline \multirow[t]{6}{*}{ Others } & & Font & 13 & 7.23 & Font & 21 & 6.54 \\
\hline & & Text & 23 & 5.19 & Text & 25 & 5.44 \\
\hline & & Photography & 25 & 5.02 & Yellow & 33 & 4.08 \\
\hline & & Yellow & 29 & 4.53 & Blue & 35 & 4.05 \\
\hline & & Blue & 34 & 4.08 & Photography & 36 & 3.91 \\
\hline & & White & 39 & 3.53 & White & 39 & 3.29 \\
\hline
\end{tabular}

\footnotetext{
${ }^{1}$ Percentage $=$ frequency of the label multiplying score divided by total number of labels .
}

\section{Discussion}

The findings of the research illustrate that the main attributes of the continuously rising lifestyle hotel sector appear in terms of physical environment, location, and experience, which are characteristics that reflect changes in market trends. Users shared considerable commonalities between lifestyle hotels and boutique hotels; however, the collected Instagram data demonstrate some meaningful attributes that create a sense of lifestyle hotel.

First, this research strongly suggests that a key attribute of lifestyle hotels that appeals to their customers is, by far, stylish spatial design. Just as lifestyle hotels are considered the next generation of boutique hotels, visually attractive interiors and architecture play an important role in constructing the experience of lifestyle hotels. This finding supports the previous studies that highlighted design in lifestyle hotels $[7,9,16,28-31]$. Of course, each lifestyle brand shows different interior styles; some brands show unorthodox colorful aesthetics and playful attitudes, whereas others fill their spaces with monotonous, minimal designs. Although the style may be different, design plays a role in making the lifestyle brand and its space more special. A significant part of customers' lifestyle hotel experiences included photographing the design of the space and sharing the atmosphere on their social media accounts with some cool and hip keywords. Thus, exclusive architectural design is one of the driving forces behind the younger generation's intention to visit lifestyle hotels and create social media content.

Second, lifestyle hotels can be identified in certain geospatial contexts. The results of location analysis showed that more lifestyle hotel posts were created downtown, whereas only a few boutique hotel posts tagged geographic information. Additionally, lifestyle hotel hashtag and image data contained various attributes that were related to urban lifestyle and experiences. This supports the notion that lifestyle hotels should be understood in the context of the urban region, in line with the previous studies that emphasized their 
modernity and urbanity $[7,9,16,28]$. In a sense, lifestyle hotels are obviously design-centered hotels offering personalized services just like boutique hotels, but their contemporary designs can serve as a medium for staging urban lifestyle experiences. Therefore, the geographical context influences how hotels stage such experiences in their spaces in ways that strengthen their distinct brand or identity.

Third, our findings confirmed that lifestyle hotels can be described as branded hotels, whereas boutique hotels tended to be more independent in comparison. Most conspicuously, the location and hashtag analyses showed that certain hotel brand names accounted for a large portion of the lifestyle hotel data. Guests often geo-tagged the locations of hotel brands or used brand name hashtags. Likewise, people mostly visited lifestyle hotels as branded hotels. This empirical data in this study supports the results of previous literature suggesting that a lifestyle hotel differs from a boutique hotel in terms of its managerial type: A lifestyle hotel should be understood as a branded hotel [16,27,32,34]. Therefore, even if lifestyle hotels have distinctive design and architecture, just like a small-scale boutique hotel, they can still be part of the spatial branding strategy.

Fourth, one of the ways in which lifestyle hotels differentiate themselves from boutique hotels is through the variety of experiences attached to their spaces. The results showed that most of the images belonged to the "activity" category among five typical categories defined by previous research: both outdoor and indoor activities as well as places where activities happened [22]. This contradicts the results of previous research indicating that "activity" accounted for only 15\% of overall Instagram posts [22]. In particular, lifestyle hotel images, as shared on Instagram, contained more indoor experiences, mostly showing guestrooms and hotel facilities. Additionally, the guests used hashtags related to daily life, not only about traveling, in those images. Therefore, consumption in a lifestyle hotel should not be understood in the context of accommodation, but rather from the perspective of activities taking place. As previous research underlined the idea that diverse activities and experiences created by hotel guests are crucial for future hotels [6,25], such activities have already been undertaken in lifestyle hotels.

Finally, the results indicated that lifestyle hotels were flexible and fast enough to reflect ever-changing hospitality trends. Whereas users mostly shared traditional vacation and nature experiences in boutique hotels, lifestyle hotel experiences seemed to only slightly match the traditional travel experiences. Rather, lifestyle hotels showed that they have adapted to the changing needs and preferences of consumers. The results of lifestyle hotel analysis reflect the newly emerging trends in the travel and tourism industry. For example, "hocance" (hotel + vacance) indicated that people spent their vacation in an urban hotel instead of traveling far away. As millennials visit hotels for diverse purposes $[6,24,25]$, customers no longer just visit hotels to stay, but rather to enjoy new experiences offered in lifestyle hotels. This somehow contradicts the result of a Delphi study conducted with industry experts that boutique hotels tend to be more characterized as stylish, trendy, and cool [16]. On the contrary, it supports the recent definition of the lifestyle hotel sector established by a hospitality analytics firm [34]. Even though there can be a difference between customers and industry experts, lifestyle hotels appeal to specific lifestyles reflecting the latest trends. Providing a variety of experiences tailored to trends in lifestyle hotels - the emerging hotel sector-can be a key attribute for ensuring sustainable growth in the hospitality industry.

Likewise, lifestyle hotels embrace a broader meaning derived from physical, geospatial, experiential, and even period-changing perspectives. Although this study contributes to the identification of key attributes of the rising hotel sector from the customers' point of view by analyzing user-created content, it also has several limitations. First, only Instagram data were analyzed among several image-based SNSs. Certainly, although Instagram was the most popular, this study did not collect all data that had been shared online, because it only showed a limited period of data in chronological order. Second, this study did not cover all types of empirical data related to lifestyle and boutique hotels. Therefore, future studies can extend our findings by utilizing other social media platforms for more 
generalized results. Third, we were unable to determine how each user evaluated specific attributes in detail, because this study only investigated the attributes from images and hashtags found in Instagram data. This might cause the results that intangible characteristics defined by previous studies $[7,9,16,28,29]$, such as high-tech features offered in smart hotel rooms and personalized services, were not found significantly within the present dataset.

Despite these limitations, this work has great significance in that it presents a novel methodology of utilizing social big data holistically to evaluate the essential attributes of a new type of hotel. Under the circumstances in which the characteristics of the lifestyle hotel were studied mainly from industry perspectives, this study addresses the customer perspective by analyzing user-created lifestyle hotel content on Instagram. Therefore, the results of this study will contribute to the limited knowledge regarding lifestyle hospitality and the future development of hotels. Based on the results of this study, it will be necessary to conduct future studies that can further assess users' experiences of the derived attributes.

\section{Conclusions}

Due to the growing uncertainty in the hospitality environment, the hotel industry is facing a huge crisis. Under this condition, understanding what customers value and desire and flexibly adjusting to these by broadening the role of hotels can bring great opportunities for the industry. This research investigated the key attributes that lead to the continuous growth of the lifestyle hotel sector despite the presence of many other choices in the market. By evaluating the attributes of a newly emerging and growing concept (i.e., the lifestyle hotel) through social big data, this study suggests which aspects hotel management should focus on in the future.

In this research, it is evident that behind the success of the lifestyle sector is the specialty of lifestyle hotels, which are distinct from boutique hotels. The results of this study demonstrate that the design, geospatial characteristics, diversified experiences, and ability to adapt to recent trends are the most important attributes of lifestyle hotels. These findings support the literature, which highlights the idea that stylish architecture and design-centered characteristics are crowd-drawers even though empowered personalized services and high-tech touches in the guestroom could not be found. Instead, lifestyle hotels can be understood as places where various activities happen, thus reflecting up-to-date consumer-driven trends in the urban context. Thus, for the sustainable growth of new and current hotels, this study implies some key attributes that should not be missed. Moreover, hospitality brands must be able to flexibly change and adjust their spatial programs in order to adapt to updated hospitality trends, as revealed in the hashtags "staysafe" and "hocance" in this research.

It is inevitable for hotel brands to continuously ask how and in what ways their environments and experiences could be better designed. Therefore, although hospitality experiences and perceptions of a place have been studied qualitatively before, this study suggests a big data approach for understanding the present and future strategies applied in such places. In the face of rapidly changing market trends, using an approach featuring deep learning can provide an opportunity for the hospitality sector to enhance competitiveness and ensure sustainability in much broader contexts.

Author Contributions: Conceptualization, Y.H. and H.L.; methodology, Y.H.; software, Y.H.; validation, Y.H. and H.L.; formal analysis, Y.H.; investigation, Y.H.; resources, Y.H.; data curation, Y.H.; writing—original draft preparation, Y.H.; writing—review and editing, Y.H. and H.L.; visualization, Y.H.; supervision, H.L.; project administration, H.L.; funding acquisition, H.L. All authors have read and agreed to the published version of the manuscript.

Funding: This work was supported by the BK21, funded by the Ministry of Education of Korea.

Institutional Review Board Statement: Not applicable.

Informed Consent Statement: Not applicable. 


\section{Data Availability Statement: Not applicable.}

Conflicts of Interest: The authors declare no conflict of interest.

\section{References}

1. Zervas, G.; Proserpio, D.; Byers, J. The Rise of The Sharing Economy: Estimating the Impact of Airbnb on The Hotel Industry. J. Mark. Res. 2017, 54, 687-705. [CrossRef]

2. Byrd, J. HVS Industry Statistics Update-Q4 2019. Available online: https:/ /www.hvs.com/article/8657-HVS-Industry-StatisticsUpdate-Q4-2019 (accessed on 19 December 2020).

3. U.S. Hotel Profits Fell $84.6 \%$ in 2020. Available online: https://www.hotelnewsresource.com/article114256.html (accessed on 2 February 2021).

4. 2020 U.S. Hotel Forecast Slightly Upgraded; Full Recovery Still Unlikely Until 2024. Available online: https: / / str.com/pressrelease/2020-us-hotel-forecast-slightly-upgraded-full-recovery-still-unlikely-until-2024 (accessed on 3 February 2021).

5. Hilberts, M. Redesigning the Guest Experience | Dialogue 32 | Gensler. Available online: https://www.gensler.com/researchinsight/publications/dialogue/32/redesigning-the-guest-experience (accessed on 2 February 2021).

6. McCleese, G. The Gensler Experience Index: Hospitality | Dialogue 32 | Gensler. Available online: https://www.gensler.com/ research-insight/publications/dialogue/32/the-gensler-experience-index-hospitality (accessed on 18 November 2020).

7. Freund, D. Seeking the "Ultimate Hotel Experience". Available online: https://www.researchgate.net/profile/Daniela_Freund/ publication/228585213_SEEKING_THE_ULTIMATE_HOTEL_EXPERENCE/links/570b69f908ae2eb942212e33.pdf (accessed on 1 November 2020).

8. Pizam, A. Lifestyle Hotels: Consistency and Uniformity vs. Individuality and Personalization. Int. J. Hosp. Manag. 2015, 46, 213-214. [CrossRef]

9. Milburn, R.; Stotts, S.; Hall, L. Standing Out in a Crowd: PricewaterhouseCoopers' Fourth European Lifestyle Hotel Survey 2006; Hospitality Directions-Europe Edition; PricewaterhouseCoopers: London, UK, 2006; pp. 1-12.

10. Schmidt, P. The Proliferation of Lifestyle Hotel Brands: Differentiate or Die. Available online: https://www.luxury-branding. com/library/lifestyle-hotel-brands-differentiate-die (accessed on 30 September 2020).

11. Asaf, S. Accor opens first Mondrian hotel in Asia. Available online: https://www.businesstraveller.com/business-travel/2020/0 8/22/accor-opens-first-mondrian-hotel-in-asia (accessed on 2 February 2021).

12. No, A. Kolon LSI Grand Opening of Lifestyle Hotel “Hotel Poco Seongsu”. Available online: http:/ / www.hotelrestaurant.co.kr/ news / article.html?no=7766 (accessed on 2 February 2021).

13. Park, S. GS Parnas Hotel Restarts Targeting Gangnam Area... The Key is to Improve Revenue. Available online: https: / / www.shinailbo.co.kr/news/articleView.html?idxno=1348120 (accessed on 3 February 2021).

14. Lee, S. Seoul Tourism Foundation Said, "COVID-19 is an Opportunity to Develop Domestic Tourism ... Domestic Travel also Needs a Premium Strategy". Available online: https:/ /www.hankyung.com/life/article/2020120988851 (accessed on 3 February 2021).

15. King, D. Defying definition: 'Lifestyle' Hotels. Available online: https://www.travelweekly.com/Travel-News/Hotel-News/ Defying-definition-Lifestyle-hotels (accessed on 2 February 2021).

16. Jones, D.; Day, J.; Quadri-Felitti, D. Emerging Definitions of Boutique and Lifestyle Hotels: A Delphi Study. J. Travel Tour. Mark. 2013, 30, 715-731. [CrossRef]

17. Saravanakumar, M.; SuganthaLakshmi, T. Social Media Marketing. Life Sci. J. 2012, 9, 4444-4451.

18. Aramendia-Muneta, M.; Olarte-Pascual, C.; Ollo-López, A. Key Image Attributes to Elicit Likes and Comments on Instagram. J. Promot. Manag. 2020, 27, 50-76. [CrossRef]

19. Rainie, L.; Brenner, J.; Purcell, K. Photos and Videos as Social Currency Online; Pew Internet \& American Life Project: Washington, DC, USA, 2012; pp. 23-29.

20. Pullman, M.; Robson, S. Visual Methods: Using Photographs to Capture Customers' Experience with Design. Cornell Hotel Restaur. Adm. Q. 2007, 48, 121-144. [CrossRef]

21. Guerrero, P.; Møller, M.; Olafsson, A.; Snizek, B. Revealing Cultural Ecosystem Services Through Instagram Images: The Potential of Social Media Volunteered Geographic Information for Urban Green Infrastructure Planning and Governance. Urban. Plan. 2016, 1, 1-17. [CrossRef]

22. Hu, Y.; Manikonda, L.; Kambhampati, S. What we instagram: A first analysis of instagram photo content and user types. In Proceedings of the International AAAI Conference on Web and Social Media; AAAI Press: EL Palo Alto, CA, USA, 2014.

23. Laws, E.; Thyne, M. Hospitality, Tourism, And Lifestyle Concepts. J. Qual. Assur. Hosp. Tour. 2005, 5, 1-10. [CrossRef]

24. Liu, C.; Wang, Y.; Chiu, T.; Chen, S. Antecedents and Outcomes of Lifestyle Hotel Brand Attachment and Love: The Case of Gen Y. J. Hosp. Mark. Manag. 2017, 27, 281-298. [CrossRef]

25. Hospitality and Leisure Trends 2019. Available online: https://www.pwc.com/gx/en/ceo-survey/2019/Theme-assets/reports/ hospitality-leisure-trends-report-2019.pdf (accessed on 3 February 2021).

26. 8 Boutique \& Lifestyle Hotel Trends to Watch in 2015-The Boutique and Lifestyle Hotel Landscape is Currently Experiencing Unprecedented Growth. Available online: https:/ /www.hospitalitynet.org/news/4069217.html (accessed on 5 September 2020).

27. McKenney, S. The Boutique and Lifestyle Report 2014 I Hotel Analyst. Available online: https://hotelanalyst.co.uk/shop/theboutique-and-lifestyle-report-2014 (accessed on 29 October 2020). 
28. Fawaz, Z. Lifestyle Hotels: The Emergence of a New Creative Class. Available online: https://www.hospitalitynet.org/file/1520 05607.pdf (accessed on 3 February 2021).

29. Kosar, L. Lifestyle Hotels: New Paradigm of Modern Hotel Industry. Tur. Posl. 2014, 14, 39-50. [CrossRef]

30. Baek, J.; Choe, Y.; Ok, C. Determinants of Hotel Guests' Service Experiences: An Examination of Differences between Lifestyle and Traditional Hotels. J. Hosp. Mark. Manag. 2020, 29, 88-105. [CrossRef]

31. Cheng, J.; Tang, T.; Shih, H.; Wang, T. Designing Lifestyle Hotels. Int. J. Hosp. Manag. 2016, 58, 95-106. [CrossRef]

32. Ricca, S. HNN-Report Defines Boutique, Lifestyle, Soft Brand. Available online: http://www.hotelnewsnow.com/articles/2556 1/Report-defines-boutique-lifestyle-softbrand (accessed on 18 October 2020).

33. Craig, D. What is Lifestyle? Available online: https://boutiquelodging.wordpress.com/2010/10/15/what-is-a-lifestyle-hotel (accessed on 2 February 2021).

34. Hotel Types. Available online: https:/ /str.com/resourcesglossary/hotel-types (accessed on 4 February 2021).

35. Jaber, A. Social Media Success Strategies for Boutique and Lifestyle Hotels. Available online: https://blla.org/social-mediasuccess-strategies-for-boutique-and-lifestyle-hotels (accessed on 2 February 2021).

36. Richter, F. Infographic: Instagram's Rise to 1 Billion. Available online: https://www.statista.com/chart/9157/instagrammonthly-active-users (accessed on 30 December 2020).

37. Mukhina, K.; Rakitin, S.; Visheratin, A. Detection of Tourists Attraction Points Using Instagram Profiles. Procedia Comput. Sci. 2017, 108, 2378-2382. [CrossRef]

38. Boy, J.; Uitermark, J. Reassembling the City Through Instagram. Trans. Inst. Br. Geogr. 2017, 42, 612-624. [CrossRef]

39. Bahtar, A.; Muda, M. The Impact of User-Generated Content (UGC) on Product Reviews Towards Online Purchasing-A Conceptual Framework. Procedia Econ. Financ. 2016, 37, 337-342. [CrossRef]

40. Silva, T.; Melo, P.; Almeida, J.; Salles, J.; Loureiro, A. A Picture of Instagram Is Worth More Than A Thousand Words: Workload Characterization and Application. In Proceedings of the 2013 IEEE International Conference on Distributed Computing in Sensor Systems, Cambridge, MA, USA, 20-23 May 2013.

41. Toscano, P. Instagram-City: New Media, and the Social Perception of Public Spaces. Vis. Anthropol. 2017, 30, 275-286. [CrossRef]

42. Jaakonmäki, R.; Müller, O.; vom Brocke, J. The Impact of Content, Context, and Creator on User Engagement in Social Media Marketing. In Proceedings of the 50th Hawaii International Conference on System Sciences, Waikoloa Village, HI, USA, 4-7 January 2017.

43. Giannoulakis, S.; Tsapatsoulis, N. Evaluating the Descriptive Power of Instagram Hashtags. J. Innov. Digit. Ecosyst. 2016, 3 , 114-129. [CrossRef]

44. The Urban Planning System of Seoul, 2. 2020 The Urban Planning System of Seoul. Available online: https://opengov.seoul.go. $\mathrm{kr} /$ public/11179 (accessed on 2 December 2020).

45. Martin, G. GEPHI-Introduction to Network Analysis and Visualization. Available online: http:/ /www.martingrandjean.ch/ gephi-introduction (accessed on 18 November 2020).

46. Vision AI | Derive Image Insights via ML I Cloud Vision API. Available online: https://cloud.google.com/vision (accessed on 29 November 2020).

47. Baker, J. The Role of The Environment in Marketing Services: The Consumer Perspective. Serv. Chall. Integr. Compet. Advant. 1986, 1, 79-84.

48. Baker, J.; Grewal, D.; Parasuraman, A. The Influence of Store Environment on Quality Inferences and Store Image. J. Acad. Mark. Sci. 1994, 22, 328-339. [CrossRef]

49. Evans, J.; Berman, B. Principles of Marketing; Prentice Hall: Upper Saddle River, NJ, USA, 1995.

50. Olahut, M.; El-Murad, J.; Plaias, I. Store Atmosphere: Conceptual Issues and Its Impact on Shopping Behavior. In Proceedings of the International Conference "Marketing—from Information to Decision”, Cluj, Romania, 19-20 November 2012; pp. 317-343.

51. Turley, L.; Milliman, R. Atmospheric Effects on Shopping Behavior: A Review of The Experimental Evidence. J. Bus. Res. 2000, 49, 193-211. [CrossRef]

52. Latapy, M. Main-Memory Triangle Computations for Very Large (Sparse (Power-Law)) Graphs. Theor. Comput. Sci. 2008, 407, 458-473. [CrossRef] 